\title{
Health status of transitional resettlement sites after the earthquake in Mianyang city of Sichuan province
}

\author{
Ying-Hua Li, Ling Qian, Xue-Qiong Nie, Li LI, Xian-Peng Meng, Jin-Bin Zhang, Li Tong, Li \\ Xiao, He Xing, Chang-Sheng Huang, Tao Hu, Yan Ning, Yan Chen, Yu Ma, Mao-Xuan Tao \\ Chinese Center for Health Education, Beijing, China; liyinghua729@sina.com
}

Received 5 August 2009; revised 1 September 2009; accepted 1 September 2009.

\begin{abstract}
Objective: To understand the health status of transitional resettlement sites and the needs of residents on health education, and to provide basis for conducting health education after ear- thquakes and other public emergencies. Method: From May 31 to June 2, 2008 (19 to 21 days after the earthquake), field observation, questionnaire survey, and structured interviews were conducted in five transitional resettlement sites. Information on health status, health service, health education, and residents' needs on health education was collected. Results: 430 questionnaires were distributed and 424 valid completed ones were returned. Food and water were adequately supplied. Clinics for health assistance were established and environment disinfecting was conducted regularly by public health professionals. Health education was available to residents. The large proportion $(98.6 \%, 97.9 \%$, $88.7 \%$, and $93.2 \%$ respectively) of the residents acknowledged that water supply, food supply, lavatories, and health service were adequate to fulfill basic needs. The overall disease incidence of surveyed residents was $44.8 \%$, and diarrhea and fever with respiratory symptoms were the most common diseases. Among residents' needs on disease prevention knowledge and skills, basic knowledge of infectious diseases was most desirable $(49.8 \%)$, and safety knowledge of water uses was secondarily most desirable (36.8\%). The most favored approach of obtaining knowledge was watching television. Conclusions: In the period of 20 days after the earthquake, Living security, health facilities, and health care service could satisfy residents' basic needs. Post-disaster health education should concentrate on basic knowledge and skills of
\end{abstract}

communicable diseases and health- risky behavior. Timely distributing disease prevention materials could be effective.

Keywords: Earthquake; Disaster Areas; Health Status; Health Education; Needs;

\section{INTRODUCTION}

On May 12, 2008, an earthquake with magnitude 8.0 hit Wenchuan, Sichuan Province. The quake caused thousands of deaths and injured, destroyed buildings and roads, and brought about huge financial loss. In the affected area, water and electricity supply were interrupted, and health care facilities and systems were enormously damaged, which resulted in the high risk for the outbreak and epidemic of intestinal communicable diseases, vector-borne diseases, food-borne diseases, diseases of natural focus, and infectious diseases transmissible between human and animals. Food and water safety, environmental health, health care service, and post-earthquake health education were the most important issues in disaster relief. To understand the health condition of transitional resettlement sites and residents' needs on health education, Health Education Institute, Chinese Center for Disease Control and Prevention (China CDC) (Note: now named Chinese Center for Health Education/ Heath News Communication Center, Ministry of Health of China) conducted this study from May 31 to June 2, 19 to 21 days after the earthquake.

\section{METHODS}

\subsection{Participant}

The resident in five transitional resettlement sites in Mianyang city, Sichuan Province were surveyed by the same questionnair, and they were from Beichuan county, one of the worst-hit areas. Four hundred and thirty questionnaires were distributed, and four hundred and twenty four valid questionnaires were re- 
turned. Sixty participants (14.2\%) were currently living in Huangtu transitional resettlement sites, seventy two $(17.0 \%)$ in Anzhou driving school, one hundred and fourteen $(25.9 \%)$ in Leigu, Beichuan, and sixty eight $(16.0 \%)$ in Gaoxin. Participants were Beichuan County residents, 208 males and 216 females. The average age was $35.3 \pm 13.3$, the minimum age was 10 and the maximum age 84 . Most of them $(70.5 \%)$ had an elementary or middle school degree, and $78.3 \%$ of them were from Qiang minority race.

\subsection{Sampling Methods}

Convenience sampling method was used to select five sites for observation and participants for survey. Age and gender were proportionally distribute.

\subsection{Observation}

Administrators examined the heath condition, health care, and health education at transitional resettlement sites. Collected information included water and food supply, living health condition, environmental health (i.e., lavatories, and garbage collection and management), health care and drug supply, and the condition of health education.

\subsection{Questionnaire Survey}

The questionnaire was self-designed and some contents were derived from environmental assessment questionnaire developed by China CDC and WHO [1-3], including several dimensions: water and food supply, health condition, health care, incidence of diseases, and postdisaster needs. Participants were interviewed face-toface by administrators.

\subsection{Personal In-Depth Interview}

Participants were randomly selected from those who were recruited for questionnaire survey. Interviews focused on post-disaster water and food supply, personal hygiene stuff, the interruption of cooking food, residents' evaluation on health education materials, and the major difficulties they were facing.

\subsection{Quality Control Survey Administrators Received Standardized Trainings}

They were guided and supported by local health departments. Participants were informed of the intent and importance of the study. Leaders of each survey group supervised the information collection process and assessed every returned questionnaire

\subsection{Statistical Analysis}

Epi data 3.0 was used to help data entry, and SPSS 13.0 was used to conduct statistical analysis.

\section{RESULTS}

\subsection{Health Condition and Health Care}

It was indicated by observation and survey that there was sufficient drinking water and food supply in transitional sites. Lavatories were enough to serve temporary residents. Every transitional site had established temporary health assistance and professionals to carry out environmental disinfection. Health education in form of health materials, posts, lectures, and volunteer in-door health promotion was delivered. However, water for living was not adequate at several sites, and the types of medicine were limited, as shown in Table 1 and Table 2.

\subsection{Diseases and Sought for Health Care}

Fifty eight participants (13.7\%) ever had diseases or symptoms. Diarrhea (54.2\%) and fever with respiratory symptoms $(32.1 \%)$ were the most common health problems.

\subsection{Health Education Condition and Needs}

\subsubsection{Residents' Health Knowledge, Belief and Practice}

Participants had some health-related knowledge and high level of awareness of drinking water safety and rabid. However, unhealthy behaviors occurred among residents, including drinking uncooked or unprocessed water, using domestic water that had not been disinfected, and failing to discharge leftovers as shown in Table 3.

\subsubsection{Health Education Needs}

In response to the question of the two most desirable things, 101 participants (23.8\%) expressed that one of them should be health and disease prevention knowledge, while the majority of them supported that they should be the living necessities including water, food, and residence. Thirteen participants thought that they did not need any assistance. In response the question of the two most desirable medical assistances, 188 participants (44.3\%) supported that one of them should be diseases prevention knowledge and skills, while the majority of them wanted convenient health care service. Twenty six participants $(6.1 \%)$ thought they did not need any health assistance. When it came to knowledge and skills of diseases prevention, basic information about communicable diseases was most favored, as shown in Table 4.

\subsubsection{Where to Access the Knowledge and Skills of Disease Prevention}

Participants gained knowledge and skills mainly from the health education materials, including booklets, brochures, foldouts, and posts, and the programs broad casted by the speakers in transitional sites were the most popular strategy to deliver health education. The most favorable way is television and materials. 


\subsection{Personal Interview Results}

One hundred and thirteen participants were interviewed. Twenty eight $(24.8 \%)$ were currently living in Huangtu transitional resettlement sites, twenty five (22.1\%) in Anzhou driving school, thirty six (31.9\%) in Leigu, Beichuan, eighteen (15.9\%) in Yong'an, and six $(5.3 \%)$ in Gaoxin. There were 43 males $(38.1 \%)$ and 70 females $(61.9 \%)$. The average age was $40.3 \pm$
6.5 , the minimum age was 10 and the maximum age was 71 . Most of them (78.9\%) were from 18 to 59 years old.

The percentages of participants who experienced interruption of food, drinking water, domestic water, lavatory, safe living places, health care, bathroom stuff, and food processing stuff were $45.0 \%, 45.5 \%, 44.4 \%, 46.2 \%$, $53.3 \%, 48.1 \%, 53.8 \%$ and $83.0 \%$, respectively.

Table 1. Health condition and Health care.

\begin{tabular}{|c|c|c|}
\hline Items & Condition & Identified problems \\
\hline Food & $\begin{array}{l}\text { Collectively and adequately supplied; Mainly } \\
\text { packaged food; Infant formula milk powder sup- } \\
\text { plied; A few cooked food supplied. }\end{array}$ & $\begin{array}{l}\text { Singleness of food types; Impossible } \\
\text { for cooking processing. }\end{array}$ \\
\hline Drinking water & Mainly bottled; Collectively supplied. & Cooked water supply not sufficient \\
\hline Domestic water & $\begin{array}{l}\text { Water disinfection by big water processing equip- } \\
\text { ments; Collectively supplied; Water collection sites } \\
\text { with } 50 \text { meters or five-minute walking distance. }\end{array}$ & $\begin{array}{l}\text { If water from rivers or springs was } \\
\text { used, disinfection could not be done by } \\
\text { residents. }\end{array}$ \\
\hline Residence condition & $\begin{array}{l}\text { Mainly tents set by governments; Approximately } \\
12 \text { square meters for } 8-10 \text { residents; Temporary } \\
\text { wood buildings established for health care assis- } \\
\text { tance use. }\end{array}$ & Extreme density. \\
\hline Lavatory & $\begin{array}{l}\text { Mainly dry lavatories build after the tremor; } \\
\text { Cleaned every day; Within } 50 \text { meters and five- } \\
\text { minute walking distance. }\end{array}$ & $\begin{array}{l}\text { The hygiene of the lavatories survived } \\
\text { from the tremor and commercial lava- } \\
\text { tories were not acceptable. }\end{array}$ \\
\hline $\begin{array}{l}\text { Environmental } \\
\text { health }\end{array}$ & $\begin{array}{l}\text { Most garbage cans topped and depleted every day; } \\
\text { Insecticide applied two times a day; Mosquito nets } \\
\text { distributed to children; Livestock feeding stuff } \\
\text { possible at several sites and animals fenced. }\end{array}$ & $\begin{array}{l}\text { Uncanned garbage found in transi- } \\
\text { tional sites. }\end{array}$ \\
\hline Health care & $\begin{array}{l}\text { One or more health care place for each site, within } \\
50 \text { meters and five-minute walking distance. }\end{array}$ & $\begin{array}{l}\text { Supply of medicine for chronic dis- } \\
\text { eases adequate. }\end{array}$ \\
\hline Health education & $\begin{array}{l}\text { Posts and brochures distributed; Health knowledge } \\
\text { promoted by medical professionals and volunteers; } \\
\text { Broadcasting programs available in some sites. }\end{array}$ & $\begin{array}{l}\text { Materials mainly in the form of leaflets } \\
\text { and brochures; Content deficient in } \\
\text { diversity. }\end{array}$ \\
\hline
\end{tabular}

Table 2. Residents' evaluation on health condition and health care.

\begin{tabular}{llcc}
\hline \multicolumn{1}{c}{ Items } & \multicolumn{1}{c}{ Reaction } & Number & \% \\
\hline Drinking water & Completely satisfied & 316 & 74.5 \\
& Basically satisfied & 102 & 24.1 \\
Food & unsatisfied & 6 & 1.4 \\
& Completely satisfied & 295 & 69.6 \\
& Basically satisfied & 120 & 28.3 \\
Lavatory & unsatisfied & 9 & 2.1 \\
& Completely satisfied & 222 & 52.4 \\
Lavatory condition & Basically satisfied & 154 & 36.3 \\
& unsatisfied & 48 & 11.3 \\
Commit nuisance & Clean & 341 & 80.4 \\
& Fairly clean & 61 & 14.4 \\
Mosquitoes and flies & Less clean & 22 & 5.2 \\
& Commonly & 14 & 3.3 \\
Health care & Less commonly & 73 & 17.2 \\
& Rarely & 337 & 79.5 \\
& Many & 143 & 33.8 \\
& Comparatively less & 155 & 36.6 \\
& Few & 126 & 29.7 \\
& Completely satisfied & 144 & 5.8 \\
\end{tabular}


Table 3. Health knowledge, belief, and practice.

\begin{tabular}{|c|c|c|}
\hline Questions & $\begin{array}{l}\text { The number of yes } \\
\text { responses }\end{array}$ & $\%$ \\
\hline \multicolumn{3}{|l|}{ Knowledge and belief } \\
\hline Drinking uncooked or unprocessed water could do harm to health. & 402 & 94.8 \\
\hline $\begin{array}{l}\text { Do not share washbasins and towels with relatives who had pink- } \\
\text { eye disease. }\end{array}$ & 295 & 69.6 \\
\hline $\begin{array}{l}\text { Rabid vaccine is needed after being biting or scratched by dogs } \\
\text { and cats. }\end{array}$ & 391 & 92.2 \\
\hline \multicolumn{3}{|l|}{ Behavior } \\
\hline Ever drunk uncooked or unprocessed water & 55 & 13.0 \\
\hline $\begin{array}{l}\text { Disinfected domestic water that was collected by themselves } \\
(\mathrm{n}=110)^{*}\end{array}$ & 51 & 46.3 \\
\hline Ate overdue food $(\mathrm{n}=167)^{*}$ & 6 & 3.6 \\
\hline Discharged waste water everywhere & 27 & 6.4 \\
\hline Cleaned garbage everyday & 62 & 14.6 \\
\hline Made efforts to prevent mosquitoes, flies, and rats & 195 & 46.0 \\
\hline Ventilated living places & 378 & 89.2 \\
\hline Washed hands before meals and after using the restroom. & 396 & 93.4 \\
\hline \multicolumn{3}{|l|}{ Leftover reheating $(n=163)^{*}$} \\
\hline Completely reheated & 123 & 75.5 \\
\hline Just warmed & 16 & 9.8 \\
\hline Did not reheat, because of lack of needed equipments & 19 & 11.7 \\
\hline Did not reheat, since it is not needed & 5 & 3.1 \\
\hline \multicolumn{3}{|l|}{ Separated the raw and the cooked $(n=58)^{*}$} \\
\hline Yes. & 54 & 93.1 \\
\hline No, since not allowed by living situations. & 4 & 6.9 \\
\hline No, since it is not needed. & 0 & 0.0 \\
\hline
\end{tabular}

Note:* indicated that only those ever had overdue food, needed stuff for cooking, and self collected water were surveyed.

Table 4. Participants' needs on general support, health care, and disease prevention.

\begin{tabular}{lcc}
\hline Items & Number & \% \\
\hline General supports (The most desirable two) & 259 & 61.1 \\
Safe living places & 178 & 42.0 \\
Sufficient water and food supply & 101 & 23.8 \\
Knowledge and skills of health and diseases prevention & 63 & 14.9 \\
Ability and skills of escaping from the tremor and helping each other & 26 & 6.1 \\
Psychological assistance & 65 & 15.3 \\
Others & & \\
Needs on health and disease prevention (The most desirable two) & 191 & 45.0 \\
Convenient health care service & 188 & 44.3 \\
Knowledge and skills & 182 & 42.9 \\
Disinfectants & 4 & 0.9 \\
Medicines & & \\
Needs on knowledge and skills of disease prevention & 211 & 49.8 \\
Basic knowledge of communicable diseases & 156 & 36.8 \\
Drinking water safety & 140 & 33.0 \\
Food safety & 132 & 31.3 \\
Prevent mosquitoes, flies, and rats & 126 & 29.7 \\
Local communicable diseases &
\end{tabular}


Table 5. Where to access the knowledge and skills of disease prevention.

\begin{tabular}{lcccc}
\hline \multirow{2}{*}{ Where } & \multicolumn{2}{c}{ Already gained } & \multicolumn{2}{c}{ Expected to gain } \\
\cline { 2 - 5 } & Number & \% & Number & \% \\
\hline Television & 131 & 30.9 & 195 & 46.0 \\
Broadcasting & 159 & 37.5 & 127 & 30.0 \\
Newspapers & 102 & 24.1 & 94 & 22.2 \\
Books & 61 & 14.4 & 89 & 21.0 \\
Medical professionals & 100 & 23.6 & 123 & 29.0 \\
CDC staff & 123 & 29.0 & 126 & 29.7 \\
Relatives/ friends & 62 & 14.6 & 42 & 9.9 \\
Propaganda materials & 209 & 49.3 & 160 & 37.7 \\
The speakers in tran- & 24 & 5.7 & 20 & 4.7 \\
sitional sites & 22 & 5.2 & - & - \\
Never gained & & & & \\
\hline
\end{tabular}

Although the problem of cooking food remained unresolved, other life necessities were fully supplied by governments. The total period of the interruption was controlled to be within two days at every site. The existing difficulties include the singleness of food which caused digest problems and stomach upset of the elder and children, extreme density of living places where both temperature and humidity were at a high level, lacking of bathing stuff, children education, job interruption, the loss of household asset, and financial crisis.

$86.9 \%$ of participants supported that post-earthquake health education was needed, and $41.6 \%$ of them thought that brochures and books were the best method of education since the content could contain a wide range of information, be systematic, and be understandable. 78.2\% of them had a positive evaluation toward the delivered or posted health education materials.

\section{DISCUSSION}

The survey was conducted 19-21 days after the earthquake. The results indicated that basic life necessities and health care facilities and service could fulfill residents' needs. Water and food supply were adequate, and there were sufficient lavatories and garbage recycling sites that were cleaned every day. Environmental disinfection, mosquito, fly, and rat prevention had remarkable effects. Few flies and rats were observed by residents. However, many problems had been identified. There is the risk of food safety issue since food was from outside of the earthquake hit areas [4]. The mainly supplied food was packaged noodles and cookies, which could effectively prevent intestinal infectious diseases. However, more efforts should be made to enrich the types of food and provide appropriate food to the elder and children. It was fairly crowded in temporary tents where the temperature and humidity were high. Tents were not enough to ensure family as the small unit to be accommodated. Many health care sites only had emergency drugs like anti-bacteria and flu treatment drugs, but the drugs for chronic disease such as high blood pressure and diabetes were not enough to satisfy the needs. Moreover, the bathing stuff were so insufficient that residents could not shower every day.

There were three kinds of lavatories available at each site: dry ones established after the tremor, remaining ones that survived from the tremor, and commercial mobile lavatories. The dry lavatories were the most appropriate ones for environmental health. They were easy to build at a lower cost and could serve many people. The other two kinds of lavatory could not be cleaned easily since the water supply was interrupted, which could result in the proliferation of flies and mosquitoes [5]. Additionally, commercial mobile lavatories were not easy to transport and their cost was high. Thus, it was suggested that dry lavatories should be established in time after earthquake.

The most common health problems among residents were diarrhea, fever with respiratory symptoms, heatstroke, cold, and dermatitis. The post-tsunami effects caused by stress sources such as lifestyle changes, the death of relative, and the loss of incomes could cause disorders of the immune system, make residents vulnerable to varieties of diseases. The density and humidity of the residence might be the cause for dermatitis.

The environment changed dramatically after the earthquake. If residents lacked the knowledge and willingness of disease prevention, or there were not enough health facilities such as lavatories, personal hygiene stuff, or even if related facilities were available but residents did not have a healthy behavior pattern, communicable disease could break out easily. Thus, post-earthquake health education was highly important. According to the results of the survey, residents had some unhealthy behaviors, like using non-disinfected river water as living water. Post-earthquake health education should follow the principles applying to outbreak public health emergencies, be delivered in time, and focus on those at high risk[6]. Booklets/brochures were the most favorable materials since they can have a wide range of information, be systematic and understandable, be kept easily. Television was the most method favored by the residents. It was highly appropriate for those who receive less education. As residents were being relocated, televisions should be equipped. Furthermore, the speakers at each site should be fully used to implement health education.

\section{REFERENCES}

[1] Chinese Center for Disease Control and Prevention. (2008) A quickly assessment table of the needs of the public health and disease control in earthquake areas [EB]. http://www.chinacdc.net.cn.

[2] Chinese Center for Disease Control and Prevention. (2008) The assessment keys of the food hygiene in earthquake areas in earthquake areas [EB]. http://www.chinacdc.net.cn. 
[3] WHO Regional Office for South-East Asia. (2004) Rapid needs assesment for water, sanitation and hygiene [EB]. http://www.who.org.mv/EN/Index.htm.

[4] Fan, Y.X., Cui, W.M. and Liu, X.M. (2008) The questions and countermeasures of food hygiene in Wenchuan areas with earthquake [J]. Chinese Journal of Food Hygiene (in Chinese), 20(4), 291-293.
[5] Hui, B. (2008) The deject arrangement and disease hidden trouble in earthquake areas [J]. Chinese Journal of Border Hygiene Tests and Quarantine (in Chinese), 31(3), 207-208.

[6] Hu, J.F. (2004) Heath education and heath promotion in public health emergency [J]. Chinese Journal of Health Education (in Chinese), 20(2), 126-128. 